\title{
Torrefação do Resíduo da Mandioca para Fins Energéticos
}

a Universidade Estadual Paulista Júlio de Mesquita Filho, Departamento de Engenharia de Energia, Campus de Rosana, Av. dos Barrageiros 1881, Primavera, CEP 19274-000, Rosana-SP, Brasil.

' Universidade Federal de São Carlos, Departamento de Ciências Ambientais. Rodovia João Leme dos Santos, Km 110, SP-264, Bairro do Itinga, Sorocaba-SP, Brasil.

- Universidade Estadual Paulista Júlio de Mesquita Filho, Departamento de Engenharia Mecânica, Campus de Guarantinguetá, Av. Ariberto Pereira da Cunha 333, CEP 12516-410, Guaratinguetá-SP, Brasil.

*E-mail: andrea.cressoni@unesp.br

Recebido em: 2 de Abril de 2021

Aceito em: 15 de Abril de 2021

Publicado online: 28 de Julho de 2021

\section{Cassava Waste Torrefaction for Energy Purposes}

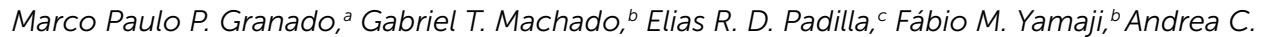 \\ De Contia, *(1)
}

\begin{abstract}
Biomass torrefaction consists of a heat treatment process that by slow heating of the material promotes the release of moisture and volatile constituents of low molecular weight. In this work, the objective was to carry out the torrefaction process in cassava rhizome in order to analyze its effect on the energy properties of the waste. The residue collected in natura was dried, ground and torrefied in two different forms: with granulated material and with material densified in briquettes; performing a torrefaction process at temperatures of 200 and $300{ }^{\circ} \mathrm{C}$, with torrefaction time of 30 and 60 minutes. According to results, the cassava rhizome torrefaction can increase its initial high heating value of $16.3 \mathrm{MJ} / \mathrm{kg}$ from 21 to $51 \%$, and decrease from $81 \%$ to $42 \%$ its volatile content; while torrefied briquettes showed little variation in their properties, except for the briquettes torrefied at $300^{\circ} \mathrm{C}$ for 60 minutes. Therefore, when performing torrefaction of densified biomass, there is a need to use higher temperature and longer torrefaction time when compared to granular biomass.
\end{abstract}

Keywords: Bioenergy; biomass; briquettes; densification

\section{Introdução}

A biomassa obtida a partir de resíduos agrícolas é uma fonte de bioenergia, cujo aproveitamento é uma alternativa oportuna, capaz de minimizar problemas ambientais e energéticos de maneira sustentável. Porém, o avanço no uso de resíduos agrícolas como combustíveis para geração de energia e calor depende da utilização de tecnologias eficientes que atribuam valor energético à biomassa.

Os resíduos de biomassa, encontrados em diversas formas e tipos, podem sempre ser utilizados como combustível. Para isso, é necessário realizar processos de transformações físicas e químicas em suas propriedades, produzindo derivados que podem ser empregados para geração de calor, eletricidade e combustível para transporte ${ }^{1,2}$. No processo de densificação energética, o material é compactado em alta pressão, para formar um produto sólido único e com alta densidade, sem alterar a composição química da biomassa. ${ }^{3-8}$ E no processo de torrefação, o material é aquecido lentamente em ambiente limitado de oxigênio até atingir temperaturas entre $200{ }^{\circ} \mathrm{C}$ e $300{ }^{\circ} \mathrm{C}$ por um tempo estipulado, promovendo a liberação da umidade e dos constituintes voláteis de baixo peso molecular da biomassa., 9-11

No Brasil, a mandioca é um cultivo agrícola presente em todos os estados brasileiros e sua produção encontra-se entre as maiores mundiais. Em 2018 a produção nacional de mandioca atingiu aproximadamente 19,4 milhões de toneladas. ${ }^{12}$ Os resíduos gerados durante sua colheita podem chegar a $316 \mathrm{~kg}$ (base seca) para cada tonelada de raiz colhida, evidenciando potencial de aproveitamento. ${ }^{13}$ A planta de mandioca pode ser dividida em parte aérea e parte subterrânea, sendo a primeira composta por ramas grossas e finas, por pecíolos e por folhas, e a segunda compostas por raízes e pela cepa.

Alguns estudos verificaram que combinar os processos de densificação e torrefação pode aumentar significativamente o atrativo dos resíduos de biomassa, promovendo o aumento no poder energético, maior higroscopicidade, estabilidade dimensional e maior densidade. ${ }^{14-16}$ Portanto, o objetivo deste trabalho foi de analisar e comparar o processo de torrefação do resíduo da mandioca com o material granulado e densificado, a fim de atribuir valor energético para a biomassa. O resíduo utilizado foi a cepa de mandioca, presente na parte subterrânea da planta, entre as raízes e os ramos aéreos. 


\section{Material e Métodos}

\subsection{Preparação e caracterização dos materiais}

A cepa de mandioca é um resíduo gerado durante a colheita da raiz de mandioca, sua coleta foi feita com pequenos agricultores familiares no assentamento Porto Maria, em Rosana/SP (22 25'36.9' S; 5248'22.3'W).

Após a coleta, realizou-se a secagem do resíduo, a fim de prevenir sua biodegradação e para realizar os processos posteriores. A secagem foi realizada em estufa laboratorial com ventilação forçada, inserindo o material com temperatura regulada em $80{ }^{\circ} \mathrm{C}$ e mantendo o processo até reduzir a umidade do resíduo para aproximadamente $12 \%$. Com o material seco, realizou-se o processo de moagem através de um moinho de facas com peneira interna com abertura de 2,00 mm. Para determinar o tamanho das partículas da biomassa após moagem, realizou-se sua classificação granulométrica utilizando um agitador de batida intermitente, seguindo como base a norma EN ISO 17827-2:2016. ${ }^{17}$

\subsection{Densificação energética}

O processo de densificação utilizado para produzir os briquetes foi realizado através de uma briquetadeira hidráulica laboratorial, com controle de pressão e temperatura. A confecção dos briquetes foi realizada utilizando temperatura de densificação regulada em $120^{\circ} \mathrm{C}$, no qual cada briquete foi confeccionado com 50 gramas de cepa de mandioca, pressão de compactação de 100 bar, tempo de prensagem de 5 minutos e tempo de resfriamento de 7 minutos. No total foram produzidos 25 briquetes cilíndricos, acondicionados em sacos plásticos para evitar ganho de umidade.

\subsection{Processo de Torrefação}

Feito os briquetes, foi realizada a torrefação da cepa de mandioca com o material granulado e densificado. O processo foi realizado em forno mufla com controle de tempo e temperatura. Os materiais foram inseridos e envelopados em forminhas de alumínio para limitar a passagem de oxigênio durante o processo, no qual foi realizado utilizando temperatura de $200^{\circ} \mathrm{C}$ e $300{ }^{\circ} \mathrm{C}$, durante 30 e 60 minutos para cada temperatura.

\subsection{Análise Química Imediata}

Para determinar as propriedades energéticas da cepa de mandioca, realizou-se análise química imediata e análise do poder calorífico superior. Estas análises foram realizadas para a cepa de mandioca crua e torrefada. A análise imediata foi realizada para determinar o teor de umidade, teor de voláteis, teor de cinzas e teor de carbono fixo, seguindo a norma NBR 8112. ${ }^{18} \mathrm{~A}$ análise do poder calorífico superior (PCS) foi realizada utilizando uma bomba calorimétrica, seguindo como base a norma ASTM D2015-96. ${ }^{19}$

\subsection{Análise do Processo de Torrefação}

Para analisar o processo de torrefação, determinou-se o índice de rendimento mássico, que define a fração da massa inicial da biomassa que permaneceu após a torrefação, conforme a Equação 1; e também o índice de rendimento energético, que resulta na fração de energia original da biomassa retida após realizar sua torrefação, conforme Equação 2.

Rendimento mássico $=\frac{\text { massa total da biomassa torrefada }}{\text { massa total da biomassa original }} \times 100$

Rendimento energético $=\frac{(\text { massa } \times P C S)_{\text {biomassa torrefada }}}{(\text { massa } \times P C S)_{\text {biomassa original }}} \times 100$

\section{Resultados e Discussão}

\subsection{Análise imediata}

Os dados obtidos pela análise imediata são apresentados na Tabela 1. Ao realizar a torrefação dos resíduos, temse a redução de umidade do material, que permite maior

Tabela 1. Análise química imediata da cepa de mandioca crua e torrefada

\begin{tabular}{|c|c|c|c|c|c|}
\hline \multicolumn{2}{|c|}{ Cepa de mandioca } & Umidade (\%) & Voláteis (\%) & Cinzas (\%) & Carbono Fixo (\%) \\
\hline \multicolumn{6}{|c|}{ Material granulado } \\
\hline \multicolumn{2}{|c|}{ mandioca crua } & 11,8 & 81,2 & 4,2 & 14,6 \\
\hline \multirow{2}{*}{$200^{\circ} \mathrm{C}$} & $30 \mathrm{~min}$ & 6,5 & 74,3 & 5,4 & 20,3 \\
\hline & $60 \mathrm{~min}$ & 6,5 & 75,4 & 6,3 & 18,3 \\
\hline \multirow{2}{*}{$300^{\circ} \mathrm{C}$} & $30 \mathrm{~min}$ & 7,4 & 42,6 & 9,4 & 48,3 \\
\hline & $60 \mathrm{~min}$ & 7,4 & 42,8 & 8,8 & 48,3 \\
\hline \multicolumn{6}{|c|}{ Material densificado } \\
\hline \multicolumn{2}{|c|}{ mandioca crua } & 10,0 & 81,2 & 4,2 & 14,6 \\
\hline \multirow{2}{*}{$200^{\circ} \mathrm{C}$} & $30 \mathrm{~min}$ & 9,2 & 79,3 & 5,0 & 15,8 \\
\hline & $60 \mathrm{~min}$ & 5,6 & 79,2 & 4,8 & 16,0 \\
\hline \multirow{2}{*}{$300^{\circ} \mathrm{C}$} & $30 \mathrm{~min}$ & 6,8 & 78,5 & 4,8 & 16,6 \\
\hline & $60 \mathrm{~min}$ & 1,4 & 34,8 & 11,5 & 53,7 \\
\hline
\end{tabular}


aproveitamento da energia disponível da biomassa durante sua combustão. Os briquetes torrefados em $300{ }^{\circ} \mathrm{C}$ por 60 minutos apresentaram a maior redução de umidade de $11,8 \%$ para $1,4 \%$.

Analisando o teor de voláteis para o material granulado torrefado temos que, em $200{ }^{\circ} \mathrm{C}$ o processo reduziu $6,9 \%$ e em $300{ }^{\circ} \mathrm{C}$ reduziu $38,6 \%$, com tempo de torrefação de 30 minutos. $\mathrm{O}$ aumento no tempo do processo para 60 minutos promoveu diferença de 1,1 e $0,2 \%$ nos resultados, respectivamente.

Já para o material densificado torrefado, o conteúdo de voláteis apresentou redução de 1,9\% para temperatura de $200{ }^{\circ} \mathrm{C}$ e redução de $2,7 \%$ para temperatura de $300^{\circ} \mathrm{C}$, com tempo de 30 minutos. Diferente do material granulado, ao aumentar o tempo de torrefação para 60 minutos, em $300^{\circ} \mathrm{C}$, o conteúdo de voláteis apresentou uma redução de $46,4 \%$, tendo uma diferença de $43,7 \%$ ao ser comparado com o tempo de 30 minutos. Nota-se que o material densificado tem uma degradação térmica de seus constituintes voláteis mais lenta comparado com o material granulado.

Ao analisar o conteúdo de cinzas após a torrefação notase um aumento referente ao percentual mássico do resíduo. Como as cinzas são compostas por matéria inorgânica, não sofrem modificação durante a torrefação, portanto seu
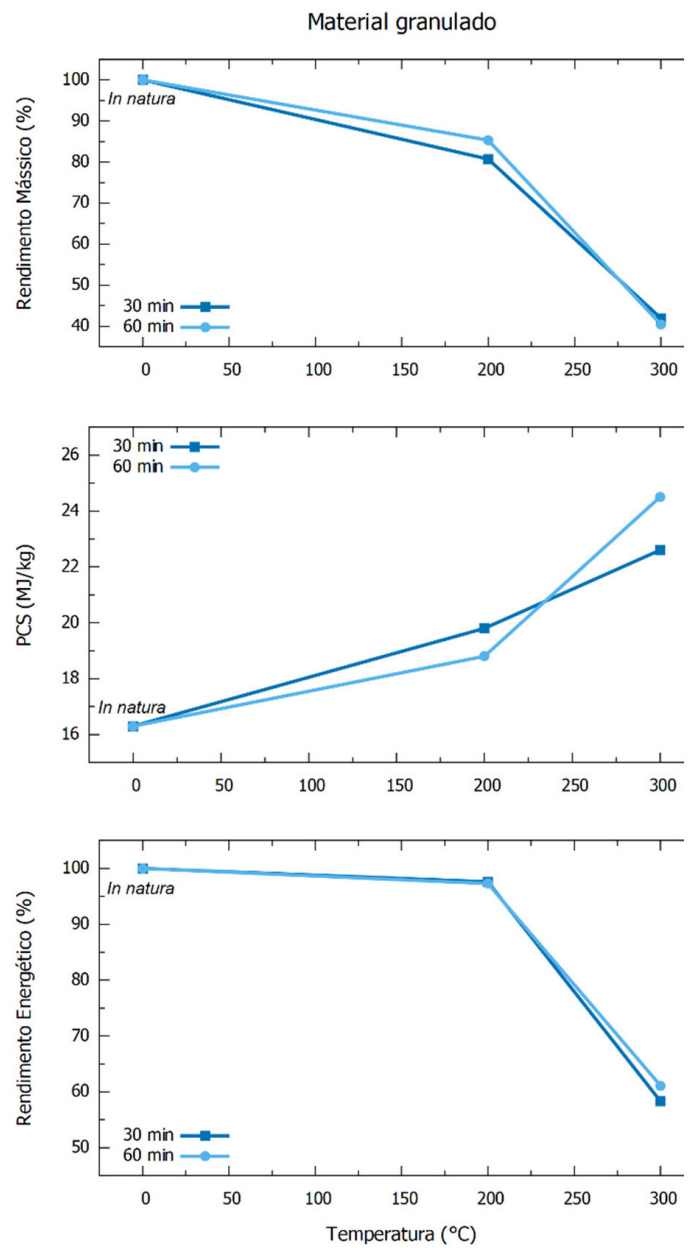

aumento ocorre devido à redução mássica do material após realizar o processo.

Após perder o conteúdo volátil, a quantidade de carbono presente no material representa o carbono fixo, sem considerar as cinzas. Portanto, conforme diminui-se o conteúdo volátil da cepa de mandioca torrefada, há o aumento de seu carbono fixo. Para o material granulado torrefado, em $200{ }^{\circ} \mathrm{C}$ teve-se aumento de $5,7 \%$ e em $300^{\circ} \mathrm{C}$ aumento de $33,7 \%$, com tempo de torrefação de 30 minutos. Para o material densificado torrefado, em $200^{\circ} \mathrm{C}$ o aumento foi de $1,2 \%$ e para $300^{\circ} \mathrm{C}$ o aumento foi de $2,0 \%$ com tempo de 30 minutos.

Com o aumento no tempo de torrefação, o processo que apresentou grande diferença no resultado foi o material densificado torrefado em $300{ }^{\circ} \mathrm{C}$, com aumento de $39,1 \%$ no conteúdo de carbono fixo.

\subsection{Análise do Processo de Torrefação}

Os índices de rendimento mássico e energético, bem como o poder calorífico superior da cepa de mandioca torrefada são apresentados graficamente na Figura 1. Ao analisar os gráficos de rendimento mássico do material granulado, nota-se resultados aproximados para tempo de
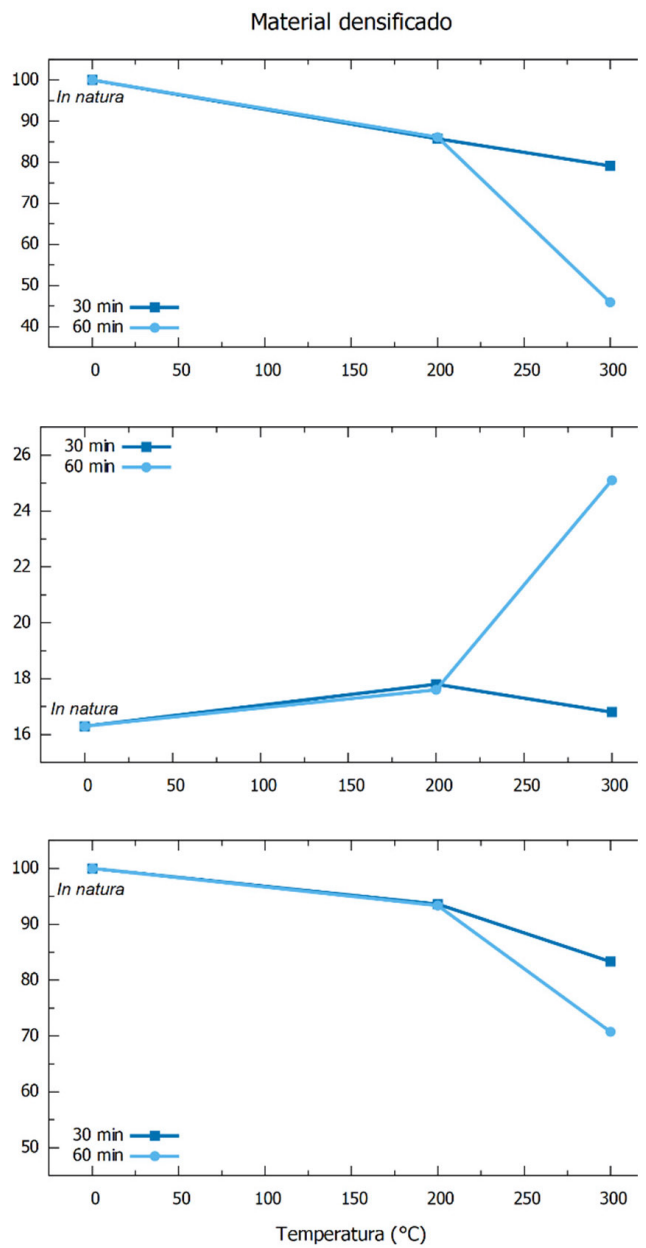

Figura 1. Índices de rendimento do processo de torrefação da cepa de mandioca com material granulado e densificado 
torrefação de 30 e 60 minutos, reduzindo a massa do material em 19,3 e $14,7 \%$ para temperatura de $200^{\circ} \mathrm{C}$ e reduzindo em 58,1 e $59,6 \%$ para temperatura de $300{ }^{\circ} \mathrm{C}$, respectivamente. Já o rendimento mássico para o material densificado, notase redução de 14,3 e $13,9 \%$ para temperatura de $200{ }^{\circ} \mathrm{C}$ e redução de 21,9 e $54,1 \%$ para temperatura de $300{ }^{\circ} \mathrm{C}$.

Ao verificar a massa dos briquetes torrefados, notou-se que a variação obtida não estava caracterizando um processo de completo de torrefação do material. De acordo com Zhang et al. ${ }^{3}$, a perda de massa da biomassa através da torrefação possui correlação com a degradação de seus constituintes. Dessa forma, tem-se que somente os briquetes torrefados em $300^{\circ} \mathrm{C}$, por 60 minutos apresentaram variação suficiente para caracterizar um regime completo de torrefação.

$\mathrm{O}$ rendimento energético apresenta, em percentual, a quantidade de energia do material que ainda está disponível na biomassa torrefada, e que não foi liberada durante sua degradação térmica. Dessa forma, para analisar o rendimento energético, deve-se levar em consideração a quantidade de massa degradada com o aumento no poder calorífico da biomassa torrefada. De acordo com os dados obtidos, tem-se que para temperatura de $200^{\circ} \mathrm{C}$, o material granulado torrefado por 30 minutos apresentou o melhor resultado de $97,6 \%$, já que apresentou maior redução de massa de $19,3 \%$ e maior aumento do PCS de $21 \%$.

Para temperatura de $300{ }^{\circ} \mathrm{C}$, o material densificado torrefado por 60 minutos apresentou o melhor resultado de $70,72 \%$, visto que apresentou redução de $54,1 \%$ em sua massa e um aumento de 50\% em seu PCS. O material densificado torrefado por 30 minutos apresentou menor redução de seu conteúdo energético, porém teve uma redução de apenas $20,9 \%$ em sua massa. Felfli et al..$^{16}$ obteve rendimento energético de $62 \%$ para briquetes de madeira torrefados em $270{ }^{\circ} \mathrm{C}$ por 60 minutos, com rendimento mássico de $54 \%$ e aumento de $15 \%$ no PCS.

\section{Conclusões}

O processo de torrefação da cepa de mandioca granulada promoveu o aumento de 14 a $51 \%$ no poder energético do resíduo, conforme maior a temperatura de torrefação. Contudo, aumentar o tempo de torrefação de 30 minutos para 60 minutos promoveu diferenças menores que $10 \%$ no poder energético.

A torrefação da cepa densificada, na forma de briquetes, apresentou aumento energético baixo, menor que $10 \%$, com exceção do processo com temperatura de $300{ }^{\circ} \mathrm{C}$ e tempo de torrefação de 60 minutos, que apresentou aumento de $54 \%$. Os resultados demonstraram processo de torrefação incompleta para os briquetes torrefados em $200{ }^{\circ} \mathrm{C}$ e os torrefados em $300{ }^{\circ} \mathrm{C}$ com tempo de torrefação de 30 minutos.

Percebe-se, portanto, que realizar o processo de torrefação utilizando o material densificado possibilita utilizar uma quantidade maior de material em uma câmara de torrefação com volume definido, contudo torna-se necessário utilizar maior temperatura e maior tempo de torrefação no processo.

\section{Agradecimentos}

Os autores agradecem o apoio financeiro da Fundação de Amparo à Pesquisa do Estado de São Paulo (FAPESP) \#2018/11837-2 e \#2018/14827-8.

\section{Referências Bibliográficas}

1. Nunes, L. J. R.; Matias, J. C. O.; Catalão, J. P. S.; Torrefaction of Biomass for Energy Applications, 1a. ed., Academic Press: New York, 2017. [CrossRef]

2. Nogueira, L. A. H.; Lora, E. E. S.; Dendroenergia: Fundamentos e aplicações, 2a. ed., Interciência: Rio de Janeiro, 2003. [Link]

3. Zhang, C.; Ho, S.-H.; Chen, W.-H.; Xie, Y.; Liu, Z.; Chang, J.-S.; Torrefaction performance and energy usage of biomass wastes and their correlations with torrefaction severity index. Applied Energy 2018, 220, 598. [CrossRef]

4. Dias, J. M. C. de S.; Santos, D. T.; Braga, M.; Onoyama, M. M.; Miranda, C. H. B.; Barbosa, P. F. D.; Rocha, J. D.; Produção de briquetes e peletes a partir de resíduos agrícolas, agroindustriais e florestais, 1a. ed., Embrapa Agroenergia: Brasília, 2012. [Link]

5. Stolarski, M. J.; Szczukowski. S.; Tworkowski, J.; Krzyżaniak, M.; Gulczyński, P.; Mleczek, M.; Comparison of quality and production cost of briquettes made from agricultural and forest origin biomass. Renewable Energy 2013, 57, 20. [CrossRef]

6. Muazu, R. I.; Stegemann, J. A.; Effects of operating variables on durability of fuel briquettes from rice husks and corn cobs. Fuel Processing Technology 2015, 133, 137. [CrossRef]

7. Brand, M. A.; Jacinto, R. C., Antunes, R.; Cunha, A B.; Production of briquettes as a tool to optimize the use of waste from rice cultivation and industrial processing. Renewable Energy 2017, 111, 116. [CrossRef]

8. Avelar, N. V.; Rezende, A. A. P.; Carneiro, A. C. O.; Silva, C. M.; Evaluation of briquettes made from textile industry solid waste. Renewable Energy 2016, 91, 417. [CrossRef]

9. Basu, P.; Biomass Gasefication, Pyrolysis and Torrefaction, 2a. ed., Academic Press: United States, 2013. [Link]

10. Chen, W.; Peng, J.; Bi, X. T.; A state-of-the-art review of biomass torrefaction, densification and applications. Renewable and Sustainable Energy Reviews 2015, 44, 847. [CrossRef]

11. Couhert, C.; Salvador, S.; Commandré, J. M.; Impact of torrefaction on syngas production from wood. Fuel 2009, 88, 2286. [CrossRef]

12. Oliveira, O. C.; Levantamento Sistemático da Produção Agrícola: Estatística da Produção Agrícola, IBGE, 2019. [Link]

13. Veiga, J. P. S.; Valle, T. L.; Feltran, J. C.; Bizzo, W. A.; Characterization and productivity of cassava waste and its use as an energy source. Renewable Energy 2016, 93, 691. [CrossRef] 
14. Faizal, H. M.; Shamsuddin, H. S.; Heiree, M. H. M.; Hanaffi, M. F. M. A.; Rahman, M. R. A.; Rahman, M.; Latiff, Z. A.; Torrefaction of densified mesocarp fibre and palm kernel shell. Renewable Energy 2018, 122, 419. [CrossRef]

15. Araújo, S.; Boas, M.A.V.; Neiva, D.M; Carneiro, A.C.; Vital, B.; Breguez, M.; Pereira, H. Effect of a mild torrefaction for production of eucalypt wood briquettes under different compression pressures. Biomass and Bioenergy 2016, 90, 181. [CrossRef]

16. Felfli, F. F.; Luengo, C.A; Suárez, J. A.; Beaton, P. A.; Wood briquette torrefaction. Energy For Sustainable Development 2005, 9, 19. [CrossRef]
17. International Organization for Standardization. ISO 178272:2016: Solid biofuels — Determination of particle size distribution for uncompressed fuels - Part 2: Vibrating screen method using sieves with aperture of 3,15 $\mathrm{mm}$ and below. [Link]

18. Associação Brasileira de Normas NBR 8112:1986: Carvão vegetal - Análise imediata - Método de ensaio, Rio de Janeiro. [Link]

19. Standard Test Method for Gross Calorific Value of Coal and Coke ASTM D 5865, 2010. [Link] 